\title{
Las relaciones de trabajo en el Perú
}

\author{
Por el DR. JORGE DEL BUSTO VARGAS, \\ Catedrático de Filosofía del Derecho.
}

Nos toca esta noche desarrollar el segundo de los temas de esta Semana relativo a las relaciones de trabajo en el Perú.

Antes que nada, es preciso delimitar el campo que será objeto de nuestro enfoque. Esta ponencia se contrae exclusivamente al problema del trabajo en el Perú cuando dicho trabajo se desarrolla dentro de una empresa, en una relación de dependencia frente $\alpha$ un principal. No vamos a abordar el problema del trabajo en el Perú en términos generales, lo que implicaría el análisis de otras formas de labor en las que no existe la debida relación de dependencia, como son la actividad del campesino no asalariado, intimamente vinculada al problema de la tenencia de la tierra y la de los que ejercen una profesión liberal sin contrato de empleo. Y dentro del terreno escogido consideraremos preferentemente la situación del obrero, que es quien en el sentir dęl Episcopado Peruano expuesto en la Carta Pastoral de 25 de enero de 1958, cuyas directivas inspiran la presente Semana, requiere nuestra más pronta atención.

Aún con las precisiones que hemos hecho, el tema es tan vasto $Y$ plantea tantas interrogantes que su adecuado tratamiento demandaría no una ponencia sino una Semana Social entera. Ei trabajo ocupa un lugar decisivo dentro del logro de las finalidades de la vida humana, $\mathrm{y}$, por ello, su consideración suscita múltiples cuestiones, todas ellas de interés vital. Por otra parte, por el incipiente o casi nulo desarrollo de la investigación social en el Perú, la mayor parte de estos tópicos, por no decir todos, apenas han sido tratados y yacen en el nivel de las generalizaciones empíricas. Más que en la etapa de las soluciones, nos encontramos todavía en el del planteamiento de las preguntas. Despertar el interés de los católicos en el Perú por estas cuestiones para que tomen conciencia de la gravedad de los problemas que en ellas se plantean y de la urgencia de solucionarlos, constituye uno de los principales objetivos de esta Semana. El concepto y la práctica de las relaciones de trabajo dependen de 
la noción y de la vivencia misma de la empresa que da nacimiento a tales relaciones.

Entre las varias maneras de entender y de vivir la empresa $y$, consecuentemente, de entender y de vivir las relaciones de trabajo, nos interesa llamar la atención sobre dos que difieren radicalmente: la liberal y la cristiana.

Para el liberalismo, la empresa es la entidad en la que convergen todos los factores de la producción y de la que divergen o dimanan todas las rentas. Dentro de esta concepción despersonalizada, el trabajo es solo uno de los factores de la producción, una energía aplicada por el trabajador a la elaboración de un producto o a la prestación de un servicio. El salario es el precio pagado por esta energía, precio que integra los costos de producción, junto con lo desembolsado por la materia prima y por el aprovechamiento de otras formas no humanas de energía. El trabajador es un mero portador de fuerzas utilizables cuyo único vínculo con la empresa es el contrato de trabajo, por el que conviene con el principal en emplear sus fuerzas en beneficio de la emprsa a cambio del salario estipulado.

La concepción cristiona considera las cosas de modo muy diferente. Para ella, la empresa es una asociación voluntaria y libre de personas humanas que vinculan entre sí, organizándolos, los diversos factores de la producción, con el propósito común de crear determinados productos o de prestar ciertos servicios, satisfaciendo una necesidad social $\mathrm{y}$, generando al propio tiempo una riqueza que debe ser justamente distribuída entre todas las personas asociadas en esta obra común. Dentro de esta concepción, el trabajo es una actividad humana que no cabe tratar en ninguna forma que la desvincule de la persona del trabajador y el salario o remuneración de cada actividad tampoco puede ser concebido con prescindencia de los fines que persigue la persona humana al trabajar. El trabajador ya no es un simple portador de energías unido a la empresa por el solo vínculo del contrato de trabajo. Es un asociado en la obra común de la empresa que, según la expresión del Papa Pío XII, "no debe sentirse extraño en el lugar de su propio trabajo", pues, "siendo coproductor es sujeto de la empresa y no simplemente objeto".

¿Cuál de estos dos modos de entender y de vivir la empresa y las relaciones de trabajo es la que hoy prevalecé en el Perú? ¿Predomina el planteamiento teórico y la actitud próctica del liberalismo? ¿Ha penetrado algo en nuestro medio la concepción cristiana? ¿Se trata de una penetración que no ha sido mó́s allá del campo de las ideas o que cuenta ya con algunas realizaciones prácticas?

Intentaremos dar respuesta a estas preguntas a través del examen de los siguientes aspectos fundamentales de nuestro tema: $1^{\circ}$ La actitud general de patronos y trabajadores en sus reclamaciones recíprocas; 2 ? Las condiciones en que se desarrolla el trabajo; $3^{\circ}$ La remuneración del trabajo; $4^{\circ}$ El problema sindical. 
19 Actitud general de patronos y obreros en sus relaciones recíprocas.-Por regla general, los trabajadores no conciben ni sienten la empresa como algo suyo, como una obra que están realizando en común con el empresario y tampoco los directivos conciben ni sienten que los trabajadores sean parte de la empresa. Cada cual mira solo sus propios problemas y olvida que "por encima de la distinción entre dadores y prestadores de trabajo" existe "aquella más alta unidad que liga entre sí a todos los que colaboran en la producción, es decir, su ligadura y su solidaridad en el deber que tienen de proveer juntos establemente el bien común y a las necesidades de toda la sociedad". (Mons. Montini, carta de Setiembre de 1952, citada por la Pastoral del Episcopado Peruano de 1958).

Patronos y obreros se miran con desconfianza y prejuicio recíproco. El obrero ve con escepticismo y resiste a aceptar las innovaciones que introduce el patrono, que pueden reportar en provecho de la empresa y a la larga del propio trabajador, poniendo en tela de juicio la buena fe del patrono al llevar adelante este medida. Por su parte, el patrono piensa que los trabajadores estón inevitablemente predispuestos en su contra, que por tal causa van a acoger como hostilidad cualquier iniciativa personal y que nada o poco se puede hacer por mejorar esta situáción.

En la mayor parte de las empresas no existe un sistema de comunicaciones o contactos permanentes entre los directivos y los trabajadores que, por un lado, haga saber a los trabajadores el porqué de las decisiones de la gerencia y busque así una colaboración razonada del empleado u obrero como integrante interesado en la marcha de la empresa, en vez de una ejecución mecánica y despersonalizada de las instrucciones y. por otro lado, ponga en conocimiento de los directivos de la empresa las ideas, iniciativas y sugestiones de los trabajadores, fruto de su experiencia y des. velos en el trabajo que, en la mayoría de los casos, se pierden, no son debidamente aquilatadas o las presentan como propias quienes deberían limitarse a trasmitirlas.

Hace falta un mínimo de contactos directos de los ejecutivos de las empresas con los trabajadores que aliente la vivencia de la unidad de la empresa y evite que el único conocimiento de los trabajadores que tenga la gerencia sea la versión de los colaboradores inmediatos de la gerencia y que, recíprocamente, la generalidad de los trabajadores no tenga otro conocimiento de sus directivos que la versión que le dan los líderes sindicales, cuyas apreciaciones no siempre son lo suficientemente objetivas.

La frecuencia e intensidad de los conflictos laborales en los últimos años, al propio tiempo que signo de la distorción económica que vive el mundo y a la que el Perú no se sustrae, constituye también un índice del poco satisfactorio estado actual de las relaciones de trabajo y un llamado al esfuerzo que todos debemos hacer en pro de un mejor entendimiento entre trabjadores y empresarios.

Algunas de las empresas que operan en el pais han tomado ya conciencia del problema y cuentan entre sus colaboradores con especialistas en el terreno de las relacionés laborales. Es igualmente una promesa en este sentido la creación del Instituto de Relaciones Humanas en la Universidad Naciọnal Mayor de San Marcos que, siguiendo el ejemplo de otros 
países de más alto nivel industrial, ha elevado al nivel de la investigación académica la preocupación por estas cuestiones.

Por cierto que el problema no es de orden meramente técnico y que las relaciones de trabajo no mejorarán si nos limitamos a hacer ver a los trabajadores que tienen intereses solidarios con los de sus principales, sin intentar seriamente, al propio tiempo, la remoción de las causas de este estado de conflicto casi permanente a que nos hemos referido.

En la perspectiva general de estas consideraciones podemos señalar como principales causas de conflicto, por parte de los patronos, y aún de aquellos que se titulan cristianos, el alejamiento del trabajador, la falta de un trato amistoso y cristiano en los contactos con los servidores de la empresa que los considere en todo momento como seres humanos iguales a los patrones en dignidad $\mathrm{y}$ derechos fundamentales, la poca sensibilidad para con las justas y a veces urgentes reivindicaciones que plantean los trabajaciores, el regateo empleado como recurso dilatorio en la discusión de los pliegos de reclamaciones $\mathrm{y}$ el desinterés $\mathrm{y}$ desprecio absoluto por los problemas personales del trabajador.

Por parte de los trabajadores cabe destacar como reacción frente a estas actitudes las inhibiciones ante el principal, el rencor en el que por la propaganda marxista comienza ya $\alpha$ infiltrarse el odio hacia el patrono y la obligada exageración de los pliegos de reclamaciones como expediente para poder obtener finalmente algo en concreto, exageración que no tendría razón de existir si un sentimiento más acusado de justicia en la conciencia patronal llevase $\alpha$ los directivos $\alpha$ tomar la iniciativa en este sentido; adelantándose $\alpha$ reconocer a los trabajadores los derechos que el patrono sabe que asisten al obrero pero que no está dispuesto a otorgar hasta que no le sean reclamados compulsivamente.

De lo expuesto surge como una necesidad inaplazable para el país la auténtica formación cristiana del hombre de empresa que vaya más allá de las palabras, que mire, con amor a los trabajadores que son como él hijos de Dios y hermanos en Cristo y que esté dispuesto a llegar a la limitación o renuncia aún de aquello que para él constituye un legítimo derecho en aras de la armonía común.

$2^{\circ}$ Condiciones en que se desarrolla el trabajo.-iLas condiciones en que se desarrolla el trabajo en el Perú, reconocen o no-la calidad de persona humana del trabajador y la dignidad que tal carácter le confiere?

Nuestro ordenamiento constitucional y legal contiene disposiciones que reconocen abiertamente la calidad de persona humana y la dignidad del trabajador. Así, en el Título de la Constitución sobre Garantías se lee que "a nadie puede obligarse a prestar trabajo personal sin su libre consentimiento y sin la debida retribución" (Art. 55) y que "es prohibida toda estipulación en el contrato de trabajo que restrinja el ejercicio de los derechos civiles, políticos y sociales" (Art. 44). El Código Civil, al enumerar los supuestos de contrato de trabajo, menciona, entre otros, la jornada máxima de 8 horas, que ya, desde el año 1919, había sido reconocida por diversas disposiciones legales $y$ reglamentarias. La obligación del descanso semanal 
proclamada por el cristianismo desde sus orígenes, recibió el respaldo de nuestra ley civil en 1918. Las vacaciones anuales pagadas, concedidas desde muy antiguo a los Maestros del Estado y a los Miembros del Poder Judicial. son, a partir de 1932, un derecho de todo obrero o empleado. La seguridad y la higiene en el trabajo están reglomentadas por múltiples disposicionesrelativas al trabajo de fábricas, minas y explotaciones petroleras. En 1911, éramos uno de los primeros paises del mundo en tener una ley sobre accidentes de trabajo que establecía el principio de la responsabilidad patronal por los mismos, fundada en la nueva teoría del riesgo. Y la tutela de la ley se extendió también prontamente al trabajo de las mujeres y de los menores.

¿Cómo se cumple todo este régimen legal?

Podemos distinguir dos aspectos. Hay, por un lado, ciertas situaciones - las menos- en las que los presupuestos mismos fijados por la ley han sido superados por convenios de las propias partes interesadas o por iniciativa personal. Por el contrario, hay otros casos - los más- en los que el dispositivo legal o las excepciones permitidas a su cumplimiento llegan. a ser tan reiteradas que, en la práctica, el propósito de la ley queda frustrado.

Así, por ejemplo, en lo que respecta a la obligación de retribuir todo trabajo, es notorio que en muchas haciendas de nuestra Sierra los familiares de la peonada son destacados rotativamente cada semana a prestar servicios en la casa del patrón. sin que por estos servicios se les remunere, En igual condición se encuentran muchos menores traídos de la Sierra a prestar servicios domésticos en las ciudades de la Costa que sólo reciben por su trabajo una mala alimentación. $\mathrm{y}$ un albergue no siempre aceptable, mós no la remuneración en dinero que supone el contrato de trabajo según nuestro Código Civil.

En lo que se refiere a la jornada de trabajo, tenemos el caso de la labor en horas extraordinarias que, convertido en situación habitual en ciertas empresas respecto de determinados servidores, por mala organización o distribución de las tareas o por tener menos personal que el requerido, hace que las finalidades del descanso, recuperación de energías y esparcimiento perseguidas por la limitación legal a la jornada de trabajo, no se cumplen respecto de dichos servidores. Quienes renuncian al beneficio de la jornada legal lo hacen generalmente movidos por la necesidad de obtener un mayor ingreso por cuanto su sueldo o salario regular es insuficiente, pero esta posibilidad de obtener un suplemento de un jornal o sueldo inadecuado tiendo a disminuir para el trabajo en las épocas de crisis con las reducciones de costos de las empresas.

En lo relativo al descanso semanal, se va ya introduciendo en nuestro medio respecto de los empleados, la costumbre de intensificar un tanto la jornada, ampliando un tanto los horarios y reduciendo el descanso entre las medias jornadas, con el objeto de gozar el fin de la semana de dos días de descanso consecutivos, lo cual es indudablemente ventajoso. DeI mismo modo los pactos laborales existentes en algunos centros de trabajo otorgan a los obreros vacaciones anuales pagadas por períodos mayores deI de 15 días que le reconoce la Ley, aproximándolo así respecto de este beneficio a la condición de los empleados. 
En cuanto a las condiciones de seguridad y de higiene en el trabajo, mientras en una minoría de empresas estas condiciones son buenas o aceptables, en la gran mayoría de centros de trabajo la situación es clamorosamente mala y refleja una vez más el concepto que los principales tienen de sus trabajadores. El desaseo, el deplorable estado de los servicios higiénicos, la falta de luz, de aire, de amortiguación de ruidos ensordecedores. Ia existencia de aparatos de protección que sólo se proporcionan a los trabajadores onte la inminencia de una visita de inspección por parte de los funcionarios del Gobierno, la circulación de vehículos cuyo estado constituye un peligro permanente para la vida de quienes los conducen, etc., son la regla general. Aún por consideraciones puramente utilitarias o inleresadas, relacionadas con la noción y la práctica de la idea de la productividad, hoy tan en boga, y sin tener en cuenta el vínculo fraterno de caridad que el ser humano debe tener para con sus iguales en dignidad y destino, los empresarios deberían preocuparse un poco más por este aspecto tan importante de las relaciones de trabajo.

En lo relativo a accidentes de trabajo las situaciones son también diversas. Algunas empresas pagan hoy a sus servidores indemnizaciones por accidente en una proporción mayor que los topes máximos fijados por la Ley, reconociendo así la inadecuación de estos topes máximos a las: condiciones de vida que hoy imperan. En cambio, otras empresás ponen grandes dificultades para la admisión de su responsabilidad por accidentes. de trabajo o enfermedades profesionales, procediendo a despedir al servidor así no esté incapacitado para el trabajo, o pretendiendo dar el trato de afecciones comunes a las enfermedades profesionales. El número de demandas que los Tribunales de la República se ven obligados a conocer por estos asuntos, así como por el pago en general de beneficios sociales, y la proporción en que las sentencias son contrarias a las empresas, constituyen índices demostrativos de esta situación.

$\mathrm{Si}$ se hace un recuento de los diversos aspectos tocados en este punto. de la ponencia, se verá que, en materia de condiciones de trabajo la iniciativa para su fijación y mejoría ha provenido casi exclusivamente de la acción estatal o de la labor de los sindicatos a través de los pactos colectivos de trabajo y que poco ha correspondido en este sentido a la iniciativa voluntaria de la empresa. En pro de un buen ambiente para las relaciones de trabajo sería muy deseable estimular el interés y la preocupación de los directivos de las empresas por el estudio y la mejoría de las condiciones de trabajo,Es axiomático que todo lo que se haga en este sentido redundaró en bien no sólo de los trabajadores sino de las empresas mismas como comunidad viviente de trabajo.

$3^{\text {o }}$ Remuneración del trabajo. Encuestas realizadas en los países de un mayor desarrollo industrial que el nuestro han investigado cual es eI orden de preferencia que en el sentir de los trabajadores debe establecerse. entre los diversos objetivos que se proponían conseguir con su trabajo: un mejor salario, planes de previsión social más adecuados, estabilidad en eI empleo, oportunidades de promoción. Las respuestas daban ordinariamente a los reajustes salariales sólo el segundo o tercer lugar y preferían mayores 
ventajas en los planes de previsión o el aseguramiento de la estabilidad en el empleo por un cierto tiempo o más oportunidad de promoción. Este orden de preferencias significaba que en el sentir de los trabajadores sometidos a la encuesta la remuneración que percibían por su trabajo era por lo menos en principio, satisfactoria.

Si una encuesta semejante se llevara $\alpha$ cabo en el Perú, cuáles serían los resultados? No se necesita muchas perspicacia para asegurar que la mejora de los salarios ocuparía el primer lugar en el orden de preferencias, pues nadie, puede negar que ${ }_{\text {en }}$ lo que respecta a los derechos de los trabajadores en las empresas, la justa remuneración ocupa hoy en el Perú el lugar más importante.

La razón de esta importancia es obvia. Por regla general el trabajador en el Perú, llámese obrero o empleado, no percibe una remuneración por su trabajo suficiente para que subsistan él y su familia. Esta insuficiencia se agrava si se tiene en cuenta el fenómeno de la inflación que tanto nos afecta, que resta día a día poder adquisitivo a la remuneración del trabajador y que, con la ascensión ininterrumpida de los niveles de precios que desencadena impide hasta el estudio mismo de los factores que deben considerarse en la determinación de un salario justo y que hace que los aumentos salariales que obtienen los trabajadores entrañen, en la mayor parte de los casos, no un progreso en sus condiciones de vida sino sólo la recuperación total o parcial del antiguo poder adquisitivo de sus ingresos.

Como es del conocimiento de todos ustedes, las directivas pontificias señalan tres factores que deben ser tenidos en cuenta en la determinación del salario justo: las necesidades del trabajador y de su familia, la situación de la empresa $y$ los requerimientos del bien común. Analizaremos, con referencia en todo momento al Ferú, el papel de cada uno de estos tres factores de cuyo concurso armonioso depende la fijación del salario justo comenzando por el bien común, cuya realización hace posible el cabal cumplimiento de los fines de la persona y de los grupos e instituciones comprendidos dentro de la sociedad, incluída la propia empresa.

Dos son las exigençias del bien común en materia económica: a) una producción de bienes y de servicios suficiente para atender las necesidades de todos; b) el justo reparto de la riqueza así producida. Ambas contrastan con la situación del Perú, país subdesarrollado, con notorias deficiencias en su producción de bienes y de servicios $\mathrm{y}$, consecuentemente. de posibilidades de empleo y de vida trente a las presiones de una pobla: ción que crece vertiginosametne y por otra parte, país en el que la riqueza está muy desigualmente repartida, concentróndose en muy pocas manos, mientras grandes sectores de la colectividad viven prácticamente en la miseria.

Las dos exigencias del bien común en materia económica están orgánicamente unidas y se apoyan recíprocamente: el aumento del nivel de - producción debe producirse en una mayor participación del trabajador en la nueva riqueza creada $y$, a su vez, la mejora de esta participación constituye un poderoso incentivo de productividad. La última parte de este aserto está demostrado por la existencia en diversos países del mundo, incluído el 
Perú, de instituciones tales como las del salario dominical, cuya finalidad de estímulo $a$ la asiduidad y rendimiento del trabajador es evidente.

La consideración solidaria de estos dos aspectos hace ver lo unilateral de las posiciones tanto de los que quieren que en el Perú opere una inmediata y drástica redistribución de la riqueza en favor de los trabajadores, sin tener en cuenta que ello impediría la capitalización y el desarrollo del país, con daño mismo de los trabajadores que hipotecarían su futuro a trueque de una ventaja inmediata, como la de aquellos que se niegan sistemáticamente a cualquiera redistribución de la riqueza que tienda a corregir las injusticias sociales, alegando que el país es pobre y que antes que nada debe salir de tal estado de pobreza.

Dos requerimientos urgentes del bien común de nuestra Patria son, pues, el incremento de nuestro nivel de producción y la dismirución de las desigualdades económicas, hoy tan fuertes, incrementando en términos reales y no solo para compensar la devualación monetaria, la participación que las clases trabajadoras perciben en el reparto de la riqueza a través del salario-

La iniciativa en esta materia corresponde antes que al Estado, a las propias empresas. Venimos así a la consideración del segundo de los factores que intervienen en la fijación del salario justo, esto es ${ }_{\text {" }}$ la situación de las empresas en lo relativo a sus posibilidades económicas frente a los salarios que hoy pagan. Tal situación es diversa en cada una de las ramas de la economía nacional $y$, aún dentro de la misma rama, al pasar de una empresa a otra. Este es uno de los motivos por el cual no compete al Estado sino a las empresas o grupo de empresas la fijación del justo salario.

Podemos tener una idea algo aproximada de los niveles actuales de salarios en los diversos sectores de la economía nacional. Para ello hemos tomado como punto de partida los datos que aparecen en la última información a la mano que el Ânuario Estadístico dal Perú correspondiente al bienic 1956-7, publicado por la Dirección Nacional de Estadística, que consigna cifras referentes a los totales de trabajadores en actividad $\underline{y}$ de jornales pagados anualmente por las empresas que integran las diferentes ramas de la economía nacional: minería, petróleo, agricultura, manufactura, construcción, transportes, otros servicios, etc. Dividiendo el total de jornales pagados por cada sector de la actividad económica entre el número de trabajadores empleados en el mismo, se llega a una remuneración promedio para los trabajadores de dicho sector, a comienzos del año de 1957, a la que se ha agregado los aumentos generales de jornales decretados por el Gobierno en los últimos años. Los resultados son los siguientes:

1. Industria eléctrica . . . . . . . . . . .

2. Petróleo ................. ..

50.76 diario

3. Transportes ..

45.86

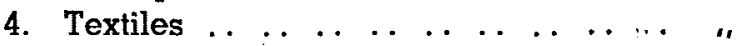

44.05

5. Manufactura en general ... ..... .

42.37

6. Minería .. ...... . . . . . . . . . . . .

38.87

7. Construcción Civil .. .. . . . . . .

33.81

8. Agricultura y ganadería .. . . . . . .

31.30

9. Pesca ..

",
",
",
"


En estos resultados sólo se ha considerado el salario efectivo, sin tomar en cuenta otras prestaciones complementarias del salario que, por ley o por pacto, ciertas empresas proporcionan a sus servidores, como son la habitación y la asistencia médica y hospitalaria gratuita para todos los trabajadores y sus familiares. Una estimación prudencial de los mismos haría pasar a la industria petrolera del segundo al primer lugar en el cuadro y a la minería del $6^{\circ}$ al $5^{\circ}$ lugar.

En cuanto a la habitación que proporciona la industria agrícola a sus servidores ello no mejora su colocación en el cuadro, tanto por la fuerte diferencia que existe respecto del nivel inmediato superior -industria do la construcción civil- como por las notorias deficiencias que por regla general acusan las "rancherías" de las haciendas en las que los trabajadores viven en condiciones infrahumanas, hacinándose frecuentemente dos o tres familias en lo que debia ser vivienda para una sola, vivienda cuya única comunicación con el exterior está constituída por una sola puerta que al cerrarse priva por completo de luz y ventilación a toda la casa, sobre cuyos pisos de tierra duermen los moradores. Salvo algunas excepciones, esta es la situación real de la habitación de los trabajadores agrícolas, no obstonte que, según una resolución suprema dada en el año 1923, las ran. cherías debieron ser sustituídas por habitaciones higiénicas, con muros de. piedra, concreto o ladrillos, pisos de concreto $u$ otro material impermeable, amplia luz y ventilación, agua potable en abundancia y desagües y letrinas que pudieran mantenerse siempre limpias.

En lo que respecta a la industria pesquera, debe destacarse el hecho de que las fábricas envasadoras suelen cerrar sus puertas varios meses en el curso del año y que, en consecuencia, el salario promedio de $\mathrm{S} /$. 16.24 diario, que se ha obtenido considerando 12 meses en el año, es, seguramente, inferior al promedio real sobre la base de los meses trabajados efectivamente.

En lo relativo a los empleados de comercio, no ha sido posible usar el mismo método referido para llegar a sueldos promedios, por las fuertes diferencias existentes entre los diversos niveles de sueldos según la posición de los distintos empleados dentro de una misma empresa, diferencias que hacen que los promedios no reflejen en la práctica situaciones reales.

Las cifras expuestas ponen de relieve el bajo nivel de salarios pagados por algunas ramas de la actividad económica nacional, muy difícil de justificarse aún haciendo la compulsa de la potencialidad económica de las empresas y habida cuenta de la pobreza del país. En especial, en lo que respecta a la industria agropecuaria en la que trabaja el $60 \%$ de la población económicamente activa del país, debe observarse que el jornal promedio de $\mathrm{S} / .22 .00$ diario sólo representa la situación de los trabajadores en las grandes explotaciones agrícolas que cumplen con presentar sus datos a la Dirección Nacional de Estadística, y que en los fundos de nuestra Sierra existen todavía jornales inversímilmente bajos, para comprender cuan aterradora es la situación del asalariado agrícola en ciertas regiones del país.

El tercer factor en el establecimiento del salario justo está representado por las necesidades del trabajador y de su familia. 
La situación descrita anteriormente nos llevará al convencimiento de que, en muchos casos, en el Perú el salario no llega siquiera a un nivel adecuado para satisfacer las necesidades del trabajador mismo como individuo. Las consecuencias de este estado de cosas se reflejan en el trabajador mismo, por regla general subalimentado y mal vestido, teniendo que recurrir al uso de estimulantes, tales como el alcohol o la coca, como fuentes supletorias de calorías y con un rendimiento mínimo en el trabajo.

Si el salario es inadecuado para el individuo, con mayor razón lo será para las necesidades de la familia del trabajador. Esta inadecuación se expresa en las viviendas en las que se ven obligados a habitar gran parte de los trabajadores, verdaderos tugurios, en los que el hacinamiento humano, la prosmiscuidad y la falta de las más elementales comodidades constituyen una de las ceusas principales de la frustración de una auténtica vida de familia a que todo ser humano tiene derecho.

La inadecuación a que acabamos de referimos, obliga entre nosotros al trabajo de la mujer y de los hijos menores, lo que aparte de debilitar la vida de familia, crea otro problema respecto del salario de la mujer, $\alpha$ la que en igualdad de condiciones de rendimiento frente al hombre, se le paga una remuneración inferior a la de éste, incumpliéndose así la regla de justicia natural proclamada por la Declaración Universal de Derechos Humanos de las Naciones Unidas y reconocida por el artículo 1571 de nuestro Código Civil que, entre los supuestos del contrato de trabajo, menciona la igualdad de salarios sin distinción de sexo por trabajo igual.

Un precepto constitucional obliga al Estado a fijar salarios mínimos para los trabajos de las diversas ramas de la economía nacional. Esto constituye un paso adelante respecto de la vieja concepción liberal que predicaba la no intervención del Estado en esta materia, aunque tales salarios mínimos están todavía muy por debajo de lo que la persona individual requiere para subsistir. Compárese por ejemplo el último sueldo mínimo de $\mathrm{S} / \ldots 550.00$ mensuales fijado por reciente Decreto Supremo para los empleados de Lima y Callao, con la cantidad de S/. 2,500.00 mensuales que nuestra Ley de Impuestos a la Renta considera como mínimo de existencia no sujeto a impuestos.

Algo se ha hecho también en materia de salario familiar. Aunque estrictamente hablando el salario familiar funciona en muy pocos casos en el Perú, que son concretamente los de los haberes de cierto nivel de empleados, en la gran o en la mediana empresa, las llamadas "asignaciones familiares", que como bien se sabe no son todavía el salario familiar sino únicamente el reconocimiento de que los sueldos o salarios básicos no bastan para el mantenimiento de la familia del trabajador, se han difundido algo más. El Estado ha establecido asignaciones familiares para sus servidores desde el año 1951 aunque la proporción en que las otorga $-\mathrm{S} / .50 .00$ por hijo- les da el carácter de un reconoçimiento todavía simbólico. En algunas empresas privadas como los Bancos, las asignaciones familiares funcionan por pacto. Mientras no lleguemos al verdadero salario familiar debemos esforzarnos por difundir y mejorar estas asignaciones para que constituyan un apoyo efectivo.

¿En las condiciones analizadas, puede funcionar el ahorro, que es otro 
de los requerimientos del salario justo? ¿Es fundada la acusación que se: formula al trabajador de que, pudiendo ahorrar, no lo hace? Evidentemente, no.

Para la generalidad de los trabajadores del Perú, la única forma de ahorro que puede cubrirlos de la eventualidad del desempleo y permitir que algunos lleguen $\alpha$ tener una pequña propiedad que los libere de la condición de asalariados, está constituída por las compensaciones por años de servicios que la Ley les reconoce. La necesidad de poner este pequeño capital a cubierto de las consecuencias de la inflación, explica el precepto que ha dado regulando el monto de dichas compensaciones o indemnizq ciones de acuerdo con el último sueldo o salario percibido por el trabajador De aquí la conveniencia que se generalice la práctica, que la Ley autoriza pero que pocas empresas acogen, de adelantar to los empleados parte o la totalidad de las indemnizaciones que les corresponderían al terminar su contrato de trabajo, con el objeto de que puedan adquirir casa habitación propia. De aquí también la justificada desconfianza que llegó a producir una huelga general de empleados, con que éstos acogieron hace 3 años la noticia de la proyectada disminución del beneficio indemnizatorio para poder dar paso a las prestaciones de invalidez y de vejez del Seguro Social del Empleado, prestaciones que responden $\alpha$ otros tines y que no equivalen al valor capital que para el empleado representa el actual beneficio indem. nizatorio. De paso mencionemos la enorme carga burocrática del mantenimiento de los seguros sociales organizado por el Estado que mengua la efectividad de la atención que por invalidez o vejez puede recibir el empleado, aparte de la fijeza de estas pensiones fuertemente sujetas a los efectos corrosivos de la inflación, como atestigua la experiencia que ya a este respecto existe con las pensiones del seguro social obrero y con las pensiones de jubilación y montepio pagadas por el Estado.

La doctrina social de la Iglesia recomienda que el régimen del salariado tienda a mejorarse con la incorporación de algunos elementos tomados del contrato de sociedad, como son la participación de los trabajadores en el capital de la empresa, en la gestión de la misma y en los beneficios obtenidos De estas tres formas posibles de participación, la última ha sido acogida por nuestra ley, pero en la práctica sólo funciona en forma de asignaciones anuales calculadas sobre la base del sueldo o salario del servidor, asignaciones cuyo pago es obligatorio cuando las ganancias de ta empresa exceden del $10 \%$ de su capital.

A nuestro juicio, la forma más viable de participación es la que reconoce a los trabajadores acciones en el capital del negocio, forma que promueve el interés del trabajador en la buena marcha de la empresa y que ya ha sido puesta en práctica por más de una compañía en el Perú.

Además del salario justo, el trabajador busca en la empresa la realización de otros objetivos como son la estabilidad en el empleo y las oportunidades de promoción.

La estabilidad ocupacional en el Perú varía de acuerdo con las épocas y con las empresas. En épocas de prosperidad económica alcanza niveles satisfactorios y tiende $\alpha$ disminuir en las crisis. Por otra parte, aI lado de empresas de reconocida solvencia moral que sólo rescinden los 
contratos de trabajo por causas justificadas, existen otras que acuden al recurso de la despedida como medio de liberarse de servidores antiguos. cuya permanencia en el empleo puede significarles una mayor carga, por el.pago de pensiones de jubilación o incremento de las indemnizaciones, 0 , simplemente, como medio de no pagar beneficio social alguno, cuando la despedida ocurre dentro del período de prueba del servidor. Debería hacerse una investigación de este tipo de empresas que, abusando de sus derechos, no pagan en la práctica beneficio social alguno a gran parte de sus. servidores.

Las oportunidades de promoción del trabajador en el Perú son, en principio, satisfactorias y ello se debe, en parte, a que se trata de un país nuevo, con una estructura social que no es tan rígida como la de otros pueblos más desarrollados. No es raro, dentro de la misma empresa, el paso de un servidor de la categoría de obrero a la de empleado, así como el ascenso de empleados desde posiciones subalternas hasta los más altos cargos directivos. Sin embargo, pocas son todavía las empresas que, en el Perú, se preocupan por este aspecto de las relaciones de trabajo, otorgando becas de perfeccionamiento a sus servidores, organizando cursos de capacitación de los mismos, llamóndolos temporalmente a desempeñar cargos de más responsabilidad, concediendo aumento de haberes no sólo por alza del costo de la vida sino también por mérito individual o promoción y dando facilidad a sus servidores para que realicen estudios superiores; no obstante que todo ello redundará en beneficio de la propia empresa. .

4 El problema sindical.-La organización sindical de los trabajadores en el Perú tiene su fundamento legal en la garantía consagrada por el artículo 27 de nuestra Constitución que reconoce la libertad de asociación y dispone que las condiciones de su ejercicio estarón regidas por la Ley. Sin embargo, hasta la fecha, muchos empresarios se oponen tenazmente $\alpha$ que sus servidores se sindiquen, alegando, con un criterio paternalista inadmisible, que sus servidores no necesitan de sindicatos para la reivindicación de sus derechos y que ellos están llanos a otorgar ciertas ventajas o beneficios a sus servidores, con la condición de que no se organicen sindicalmente. Esta posición es inaceptable porque lo que constituye un derecho para el trabajador no puede depender en su existencia de una mera concesión graciosa del principal y ha motivado el que el Estado dicte normas protectoras de los sindicatos desde que están en vías de formación, que ponen $\alpha$ cubierto $\alpha$ sus organizadores de las posibles represalias patronales.

La defensa del derecho a la sindicalización, no significa el que no reconozcamos algunos graves defectos que hoy se observan en las organizaciones sindicales y a los que debe ponerse remedio. Uno de los más señalados es la inobservancia por parte de los sindicatos, de los trámites legales a los que deben someter sus peticiones. Es frecuente que los sindicatos planteen la amenaza de huelgas en problemas en los que no han acudido todavía a los trámites previos del trato directo y de la conciliación para resolverlos. Es también común la declaración de huelgas por la junta directiva de los sindicatos, sin los requisitos exigidos de asambleas de los trabajadores, con la concurrencia mínima de las tres cuartas partes 
de los mismos, voto secreto y mayoría de votos. Buena parte de la responsabilidad de estas situaciones que desprestigian el movimiento sindical, la tienen los propios trabajadores que, por inercia, apatía o temor, no participan en la vida del sindicato y entregan prácticamente a los dirigentes sindicales, que sólo son gestores de sus compañeros de labores el poder decisorio en estos asuntos.

Es hoy también un lugar común la crítica de la infiltración de la política en los sindicatos que tergiversa los objetivos de los mismos y causa divisiones en el seno de los trabajadores, perjudiciales a los propios intereses de éstos.

Los principales objetivos a los que hoy se dirigen los sindicatos sor las reclamaciones salariales que son resueltas mediante la concertación de pactos colectivos de trabajo o las decisiones de la autoridad de trabajo, cuando no se ha llegado a un acuerdo de partes. Es necesario que estos objetivos se amplíen y se contemplen otros aspectos hoy descuidados, como son la promoción cultural del trabajador, la lucha contra situaciones en las que el trabajador resulta explotado por su propio compañero de labores, como es el caso conocido de los estibadores, el fomento del cooperativismo, etc., etc.

Párrafo aparte merece la cónsideración de lá figura del líder sindical. Para evitar los ataques que se dirigen contra la organización sindical fundados en los defectos que se suelen advertir en la persona de los líderes, es fundamental que los dirigentes sindicales procuren ser en todos sus actos un ejemplo para los demás en material de contracción a sus obligaciones en el trabajo, puntualidad, probidad, sobriedad, desinterés y abnegación.

Las virtudes que hemos enumerado para la persona del dirigente sindical, nos muestran cuan urgente es que la Iglesia en el Perú lleve a cabo la tarea que ya ha comenzado, de la formación cristiana del dirigente sindical y, a la vez que dirigentes patronqles preparen líderes sindicales que también sean auténticamente cristianos, para que ambas partes, con el pleno conocimiento de sus derechos y deberes recíprocos, a la vez que con la buena voluntad y la dación de sí mismos, que constituyen la esencia de la caridad cristiana, reconquisten a los trabajadores para la causa de Cristo, contribuyan al logro de la paz en el orden de las relaciones de trabajo y disminuyan las tensiones que hoy prevalecen y amenazan las bases mismas de nuestra civilización.

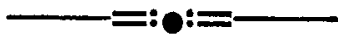

